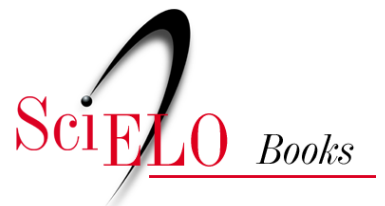

\title{
EDUFU
}

\section{A obra de Georges Snyders cultura e política como pressupostos de uma escola progressista}

\author{
Aline Helena Iozzi de Castro Serdeira
}

\section{SciELO Books / SciELO Livros / SciELO Libros}

SERDEIRA, A.H.I.C. A obra de Georges Snyders: cultura e política como pressupostos de uma escola progressista. In: BOTO, C., ed. Clássicos do pensamento pedagógico: olhares entrecruzados [online]. Uberlândia: EDUFU, 2019, pp. 189-217. História, Pensamento, Educação collection. Novas Investigações series, vol. 9. ISBN: 978-65-5824-027-3. Available from:

http://books.scielo.org/id/fjnhs/pdf/boto-9786558240273-10.pdf. https://doi.org/10.14393/edufu-978-85-7078-472-8.

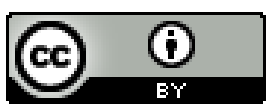

All the contents of this work, except where otherwise noted, is licensed under a Creative Commons Attribution 4.0 International license.

Todo o conteúdo deste trabalho, exceto quando houver ressalva, é publicado sob a licença Creative Commons Atribição 4.0.

Todo el contenido de esta obra, excepto donde se indique lo contrario, está bajo licencia de la licencia Creative Commons Reconocimento 4.0. 


\section{A obra de Georges Snyders: cultura e política como pressupostos de uma escola progressista}

Aline Helena Iozzi de Castro Serdeira

\section{Introdução}

Pensar a escola e as relações que ela estabelece com a sociedade - em suas determinações políticas, sociais e psicológicas - tem sido um desafio importante, especialmente desde o momento em que, no século XIX, o Ocidente erigiu a escola como a instituição capaz, por excelência, de solidificar os princípios republicanos para uma sociedade moderna e justa.

Pouco a pouco, construiu-se a ideia de uma instituição capaz de oferecer igualdade de condições para o desenvolvimento diferenciado das potencialidades. Partia-se do princípio de que iguais condições de acesso possibilitariam a todos os indivíduos o desenvolvimento de características pessoais naturalmente desiguais e necessárias à construção de uma sociedade harmônica.

A história da instituição escolar - ao longo do século XX ensinou-nos, contudo, que, embora fundamental, o ideário iluminista de uma escola igualitária e a consequente universalização do acesso ao ensino escolarizado não seriam suficientes para garantir a todos os indivíduos o desenvolvimento equilibrado de suas potencialidades 
e a inserção integral na sociedade. Aspectos próprios do "chão institucional" sobre o qual a escola se edifica foram, desde então, estudados exaustivamente com o objetivo urgente de entender o que faz da escola instrumento de exclusão e reprodução de uma ordem social não igualitária e pouco democrática.

Nas últimas décadas, estudos nas áreas de Sociologia, Filosofia, História da Educação e Didática revelaram a possibilidade de novos olhares sobre os problemas que a educação escolarizada não conseguiu ainda solucionar. Suas falhas quanto aos objetivos de promover a igualdade entre os indivíduos e o desenvolvimento de uma sociedade pautada por princípios de justiça e democracia acabaram por ser entendidas como uma gama de significados em produção contínua, favorecendo a exclusão das minorias e a construção de lógicas pelas quais o mundo e o homem são pensados unilateralmente e coisificados. Nesse contexto, a escola passou a ser vista ora como instrumento para moldar a sociedade, ora como capaz de atuar efetivamente contra as contradições, nuances e determinações da desigualdade social.

É no cerne dos debates que, no século XX, ampliaram e ressignificaram a ideia de escola moderna que se insere a obra de Georges Snyders. O presente artigo se propõe a reconstruir o itinerário da pedagogia do autor, centrada de modo intransigente na defesa de uma escola universal, igualitária, leiga e democrática.

\section{A escola como universo específico}

Georges Snyders nasceu em Paris, em 28 de abril de 1917. Foi professor da Faculté des Lettres et Sciencies Humanes de Nancy, da École Normale Superior de Paris e professor emérito da Université Sorbonne (Paris V), onde lecionou na área de Ciências da Educação. Judeu, ateu e comunista, foi preso em Lyon durante a Segunda Guerra Mundial e levado a Auchwitz em 1944. Ao longo de toda a sua obra podemos reconhecer os resquícios dessa passagem, traduzidos como repulsa intransigente a todo tipo de preconceito, 
racismo ou xenofobia, marcas claras de uma experiência dolorosa e determinante: a perseguição, o medo, a prisão e a tortura em campos de concentração. Snyders morreu em 28 de setembro de 2011, aos 94 anos, deixando como legado uma obra apaixonada e convicta, em que a educação e a escola figuram - invariavelmente - como ofício e espaço de luta, transformação e alegria.

Podemos dividir a obra de Georges Snyders em duas grandes fases. A primeira - especialmente analítica e dialógica - nos traz uma análise histórica do conjunto de teorias e autores que marcaram a história da pedagogia na França desde o século XVII. Nesses trabalhos, o autor constrói uma sintese teórica em que os traços positivos das obras analisadas são assumidos como pertinentes para a pedagogia progressista e os elementos negativos são marcados como pontos de ruptura. Esse é o instrumento que Snyders utiliza para expor suas próprias ideias sobre pedagogia, sua filosofia da educação.

A segunda fase apresenta uma extensão dos pressupostos e princípios desenvolvidos nos primeiros trabalhos e reafirma o teor democrático que o autor confere à cultura político-revolucionária e à cultura erudita. A mudança no teor dos textos consiste especialmente na forma e nos recursos com os quais o autor desenvolve suas proposições. Nesses trabalhos, Snyders já não recorre ao debate com outras correntes, mas se centra na exposição direta e sistemática dos próprios postulados.

Seu primeiro livro, La pédagogie en France aux XVII et XVIII siècles, publicado em $1965^{1}$, centra-se, por um lado, na análise dos pressupostos educativos da pedagogia jesuítica e, por outro, no estudo dos princípios educativos presentes no imaginário iluminista. O autor reconstrói, assim, a ideia de pedagogia tradicional, oferecendonos uma categoria teórica em que estão presentes as características positivas dos recursos metodológicos usados nos colégios jesuitas e o caráter sistemático e específico da instituição escolar. A partir daí, em

${ }^{1}$ Para análise de La pédagogie en France aux XVII et XVIII siècles utilizamos a referida edição francesa, de 1965. (Snyders, 1965). 
cada uma de suas obras, a educação tradicional não será tratada como aquela que transmite apenas conteúdos inúteis e pedantes, mas como locus de uma pedagogia que permite ao educando afastar-se do mundo cotidiano para centrar sua atenção no universo dos autores clássicos e, consequentemente, para se valer de todo o potencial educativo e civilizatório contido em tais obras.

Ao mesmo tempo, e por outro lado, as análises construídas pelo autor em seus primeiros livros nos mostram que os colégios - e toda a tradição pedagógica que deles decorre - rejeitavam qualquer expressão de espontaneidade infantil, tranduzindo um sentimento contraditório em relação à infância: de um lado, os adultos a viam como um ideal de pureza e bondade; por outro, percebiam as crianças como seres corruptíveis e suscetíveis a todo o mal.

O reconhecimento dessa contradição faz com que o autor recuse a desconfiança em relação à criança e proponha, como fundamento de sua pedagogia, uma confiança ilimitada no potencial educativo e progressista da infância. Para o autor, essa fase da vida deve ser pensada sempre como aquela em que é possível formar-se para o contato com o mundo adulto-erudito, sem perder, contudo, a alegria espontânea do mundo infantil e da cultura popular.

Para a construção de sua própria teoria pedagógica, Georges Snyders mobiliza, assim, todo um conjunto de conhecimentos acerca das instituições que, desde os colégios jesuítas, tem elaborado práticas e ideais da Educação Moderna. Mas, ao apropriar-se dos pressupostos da escola tradicional, os reveste de uma nova positividade: a positividade de ser escola que leva ao esforço e à disciplina intelectuais pelo confronto com os modelos da cultura elaborada e pela inserção em um universo especícifico, separado da vida e consagrado à pedagogia:

Não forcemos a idéia até à caricatura. A escola faz parte do mundo, quer ela queira quer não. Quanto mais a criança cresce mais se abre às influências exteriores e estabelece experiências directas, contactos directos com a realidade. Pretende-se, no entanto, que ela permaneça 
um lugar específico e justamente adaptado à especificidade dos novos. (Snyders, 1974, p. 38-39).

Em 1976, Snyders publica Escola, classe e luta de classes $^{2}$, expondo a necessidade urgente de reconhecer a escola como instituição capaz de conduzir as crianças das classes operárias à apropriação de um universo cultural e intelectual que lhes é, a princípio, tão estranho quanto valioso. Nessa medida, toma a cultura clássica como fundamento de uma pedagogia pautada na ideia de formar as gerações mais novas para a democracia e a tomada de consciência.

Sua teoria apresenta-se, a partir de então, explicitamente alicerçada em princípios gramscinianos. Como desdobramentos dessa filiação, podemos citar fundamentalmente a negação das teorias crítico-reprodutivistas, representadas, sobretudo, pelos trabalhos de Bourdieu-Passeron, Baudelot-Establet e Illich. Para Snyders, a escola não é apenas aparelho de reprodução ideológica, mas um universo complexo, marcado por conflitos e contradições, cujas brechas abrem espaço para a formação intelectual das massas e para a constituição de uma ordem social pautada pelo acesso universal à cultura elaborada.

A síntese dialética que permite ao autor articular ambas as filiações - à escola tradicional e a Gramsci - é também o que conduz Snyders a uma preocupação determinante: como construir uma escola que leve os alunos à tomada de consciência de suas reais condições de vida, escapando ao determinismo do senso comum? Como promover um ensino que, ao menos no ponto de chegada, se faça único e universal, permitindo, assim, a construção de uma nova relação entre trabalho e cultura, teoria e prática?

Ao defender o acesso universal à cultura erudita, Snyders não só evoca seus vínculos com o modelo escolar moderno, mas também nos leva à apreensão de que é possível um novo equilíbrio entre o trabalho manualloperário e o trabalho intelectual. Nesse sentido, Escola, classe e luta

${ }^{2}$ Utilizamos, para a análise de Escola, classe e luta de classes, a $2^{\text {a }}$ edição portuguesa, de 1981 (Snyders, 1981). 
de classes é a expressão máxima de uma teoria pedagógica cujo objetivo é formar os alunos para que consigam transformar suas relações com o trabalho e o mundo da produção e, consequentemente, para que possam formular uma concepção de mundo menos preconceituosa e mais abrangente.

Contudo, a reelaboração do senso comum depende de que os adultos tomem uma posição responsável e se coloquem como mediadores democráticos nas relações entre a criança e a cultura elaborada. Aqui, podemos dizer que, tal como os educadores tradicionais, Snyders pensa a criança como adulto em potencial: repleta de vivacidade e mobilidade, mas a exigir uma escola que, ao colocá-la em confronto com o mundo das obras-primas, a impulsione a civilizar seu comportamento e a racionalizar seu modo de pensar.

A necessidade de elaborar concepções de mundo mais claras exigiria um papel ativo por parte do professor e também por parte do aluno: esforço intelectual, estudo rigoroso e desenvolvimento de hábitos de leitura e investigação que ainda não possui, mas para os quais, no entanto, todo homem está naturalmente apto. Daí a importância de um universo especialmente construído para formar intelectualmente a criança em um duplo sentido: exigindo-lhe disciplina e construção de hábitos intelectuais e oferecendo-lhe acesso às maiores obras da cultura universal.

É cara a Snyders a ideia de conhecimento como fonte de esclarecimento e liberdade; uma ideia que se torna alicerce inequívoco de sua obra: se a cultura não pode, por princípios democráticos, se distanciar do povo, a escola, por sua vez, não pode se organizar de forma a impor, para crianças de classes sociais diferentes, conteúdos e objetivos diferentes. A luta cultural reside justamente em garantir as possibilidades de acesso universal a uma cultura também universalhumanista e técnica, histórica e política.

Nesse contexto, Snyders propõe-nos uma escola que prime pelo presente, que promova a alegria entre os jovens hoje e que se reconheça capaz de promovê-la por meio daquilo que lhe é mais específico: o 
acesso sistemático à cultura elaborada. Essas proposições nos levam a reconhecer em sua obra as marcas do caráter utópico tão característico de Gramsci e do legado iluminista.

Snyders quer a cultura clássica na escola tanto quanto a queriam renascentistas e jesuítas, Condorcet ou Gramsci. No entanto, a originalidade de seus argumentos reside no fato de que busca, também nesse aspecto, articular as duas posições: a cultura elaborada deve ser transmitida na escola a todos os alunos porque é a única capaz de levar o estudante a uma compreensão mais racional do mundo.

Snyders desenvolve, portanto, em cada uma de suas obras, dois princípios fundamentais: 1) para transformar é preciso conhecer o objeto de transformação ${ }^{3}$ e, por isso, 2) os adultos têm de assumir a responsabilidade de apresentar às crianças esse mundo que lhes é totalmente novo, inusitado e encantador, utilizando obras historicamente construídas, para que, dessa forma, possam transformar sua concepção de mundo e, por meio dela, suas condições de vida.

Reconhecemos em Snyders a imagem do educador tal como a evoca Arendt (2001), ou seja, a imagem de um educador-adulto a quem cumpre fitar e transpor o paradoxo imposto pelo mundo moderno: como proteger a criança do universo adulto, sem, com isso, deixá-la entregue às próprias fragilidades e incompletudes? Como fazer da escola universo específico (tal como o construíram os jesuítas) e, ao mesmo tempo, proteger a criança da tirania adulta (preocupação central em Rousseau)?

Para responder a tais questões, é necessário recorrer a um conceito de infância que implica a necessidade de resguardar, entre jovens e adultos, a igualdade de direitos, mas, ao mesmo tempo, a desigualdade de nível em relação ao domínio do universo cultural,

\footnotetext{
${ }^{3}$ Não obstante esse argumento fundamente toda a teoria e se faça perceber a todo o momento, vale a pena atentar para a discussão sobre a importância dos modelos culturais elaborada especificamente em Pedagogia progressista (Snyders, 1974b). O trecho, a seguir transcrito, foi retirado dessa mesma obra e deixa entrever a radicalidade com que o autor afirma este princípio: "O novo não surge do nada; consiste em aprofundar, mesmo modificando-o completamente, o que já existe” (Snyders, 1974, p. 122).
} 
cabendo ao adulto organizar o contato da criança com o universo cultural historicamente construído, transformando as obras culturais em fontes de modelos intelectuais e morais.

A proposta pedagógica de Georges Snyders impõe a seus leitores a urgência de pensar uma escola que - ao formar para a tomada de consciência e para a transformação das dificuldades impostas pela luta de classes - possibilite, a despeito de tudo, promover uma alegria especificamente escolar. Isto porque seus escritos têm por pressuposto a ideia de que a luta de classes é uma luta cultural, não sendo possível abordar economia, cultura e política separadamente. Isso posto, impõe-se fazer com que a escola atue nos dois sentidos: formar para o domínio do universo intelectual, mas de tal maneira e com conteúdos tais que os alunos também reconheçam as brechas e possibilidades já existentes para a transformação da sociedade. Trata-se de superar uma concepção ingênua de cultura escolar como desinteressada e inútil, para transformá-la em instrumento de luta pela democratização da sociedade e das relações de classe.

Em Snyders, a formação para a superação do conservadorismo social deve principiar, nesse sentido, pela apreensão das possibilidades de transformação já presentes na escola. De um lado, devemos reconhecer que a escola não é a sociedade, e que, por tal razão, a transformação de uma não implica diretamente a transformação da outra. De outro, é preciso ter sempre em mente que "o movimento para transformar a escola é uno com o movimento para transformar a sociedade: cada passo em frente vale por si mesmo e como garantia da possibilidade de tudo ser posto de novo em causa" (Snyders, 1974, p. 295-296).

\section{A escola como espaço de alegria}

A segunda fase da obra de Georges Snyders se constrói afirmando e estendendo os pressupostos explicitados até aqui. $\mathrm{O}$ autor insistirá na ideia de que é necessário, com uma atitude adulta e responsável, fazer da escola locus de uma alegria especificamente 
cultural. Ao caráter político que revestia seus primeiros trabalhos, se sobrepõe a preocupação de que o contato com as obras-primas permita não só a apreensão do mundo da cultura erudita, mas também faça das crianças "alunos felizes".

Em 1986, Snyders publica Alegria na escola ${ }^{4}$. Aqui, o autor define como alegrias imediatas e necessárias o gosto pelo presente, o sentimento de pertencimento à humanidade, a ideia de cultura como não exclusiva das classes dominantes e aberta para a ação. Como prolongamento de cada uma dessas alegrias imediatas, o autor nos traz novamente a necessidade de pensar a escola como universo complexo, capaz de abrigar a satisfação, mas também um universo de especificidades (racionalidade, esforço, obrigação de leituras e exercícios, confronto com modelos abstratos) que exigem ruptura.

Alunos felizes - publicado em $1991^{5}$ - desenvolve a ideia de que é preciso desconstruir a oposição entre cultura e natureza humana. Para tanto, seria fundamental levar o jovem à apreensão de que a humanidade, embora envolta em conflitos dramáticos, encerra sempre uma luta no sentido de promover a não opressão e, principalmente, uma mobilidade histórica pela qual é possível pensar e promover o progresso.

O que marca, fundamentalmente, a diferença das obras mais recentes de Snyders em relação a seus primeiros livros é a ênfase nas alegrias especificas que a escola pode oferecer às crianças. A alegria pode ser encontrada em relações democráticas entre alunos e professores, e também na realização e no domínio de tarefas, como os exercícios graduados e sistemáticos. No entanto, a alegria maior está posta na relação, mediada pelo universo escolar, entre as crianças e o conhecimento historicamente acumulado, relação que implica progressos pessoais (autodomínio) e intelecutais.

${ }^{4}$ Utilizamos, para a análise de Alegria na escola, a edição brasileira de 1988 (SNYDERS, 1988).

${ }^{5}$ A análise de Alunos felizes foi feita utilizando-se a edição brasileira de 1993 (Snyders, 1993). 
Cabe-nos, então, buscar entender o que significa uma tal mudança de enfoque. A ênfase na ideia de alegria escolar revela o abandono dos pressupostos gramscinianos impulsionado por um contexto histórico que desencoraja o estabelecimento de ligações diretas entre marxismo e educação no cenário pós-queda do muro de Berlim? Até que ponto o postulado de uma escola que ousa e assume a responsabilidade de educar para a alegria especificamente cultural responde a proposições tais como a elaborada por Marco Aurélio Nogueira: "tanto no país dos sovietes como no mundo inteiro, as esquerdas e os democratas precisam reinventar a si mesmos, requisito para que novas formações políticas surjam, conquistem as massas e mantenham vivo algum tipo de utopia” (Nogueira, 1991, p. 12).

Devemos reconhecer, desde o início, que o que impulsiona e dá sentido aos trabalhos de Snyders na última fase de sua obra é a ideia de que a alegria - embora represente um conjunto de possibilidades progressistas - mantém-se ainda fora da escola e dá lugar a uma passividade impressa nas relações entre as crianças e o conhecimento. A mudança no enfoque das análises não nos permite apontar uma ruptura do autor com as proposições mais explicitamente políticas; ao contrário, nos trabalhos mais recentes, somos obrigados a reconhecer a radicalização do potencial democrático e revolucionário que o autor atribui a conceitos tais como alegria escolar e satisfação cultural. Nas palavras de Snyders:

Qual a relação do que escrevi com o fracasso escolare com as dificuldades que atingem as classes exploradas e seus filhos cada vez mais duramente [...] Teria me deixado dominar pelo elitismo cada vez mais presente na sociedade? [...] Não renunciei de forma alguma, entretanto, nem à democratização da cultura, nem à da escola e à da sociedade. [...] Estou persuadido, contudo, de que a alegria cultural presente é uma das inúmeras forças que poderiam ser utilizadas para reavivar o interesse pela escola naqueles que se cansaram dela, que não encontraram nela as possibilidades para seu desenvolvimento. (Snyders, 1994, p. 159-160). 
O que se observa é que Georges Snyders, em certa medida, aceita o debate acerca dos rumos tomados pelo marxismo ortodoxo e constrói proposições críticas contra as tendências autoritárias e o engessamento das estruturas de governo nos países socialistas. Contudo, seus textos nos trazem, sempre, uma tomada de posição afirmativa. Snyders busca responder à situação de absoluta descrença e contestação com um trabalho que resgata e explicita os fundamentos progressistas e democráticos do marxismo e suas consequências no campo educacional:

O progressismo marxista está em crise e eu vivo esta crise muito vigorosamente, é natural, como todos os comunistas, como todos os marxistas. Há erros e crises. Mantenho que o essencial do marxismo permanece verdadeiro. Para mim um dos aportes essenciais do marxismo é a idéia de progresso da sociedade. Quer dizer, através de coisas horríveis, guerras, atrocidades, há um progresso (...) O marxismo mantém a idéia de progresso que é capital para os alunos, para dar-lhes confiança. (Snyders, 1995 apud Klein, 1995, p. 143).

Nesse movimento, Snyders acentua a discussão sobre o teor político das alegrias provocadas pela aprendizagem de conteúdos e práticas especificamente escolares, que, para ele, não podem estar ligadas exclusivamente ao âmbito da didática: se, por um lado, quando pensamos a escola como universo separado e diferente da vida, corremos o risco de negar a desigualdade e a luta de classes, por outro, garantimos o uso institucional e regulado do tempo, a adaptação dos conteúdos e da cultura às necessidades da infância e, como consequência, a possibilidade de o aluno compreender o universo social, as determinações históricas que marcam as relações sociais, a unidade dialética que confere e traduz os sentidos da história humana. Cada uma dessas apreensões culturais traz um acréscimo de alegria que convida e encoraja a agir para transformar o mundo. É assim que Snyders nos desvenda o teor político da alegria: 
há culturas capazes de dar satisfação. Isso significa que a caminhada em direção à verdade, à apreensão do real, dá mais satisfação, abre mais esperança que permanecer na incoerência, no aproximativo, no indeciso. Isso significa também que a satisfação da cultura pode e deve culminar em ação que mude alguma coisa no mundo, participe às forças que mudam algo no mundo. (Snyders, 1988, p. 20).

\section{A escola como espaço de confiança no progresso do mundo}

Georges Snyders repousa todo o sentido de sua pedagogia na ideia de que a juventude é passível de respeito e admiração, cabendo ao professor o papel de afirmar a positividade e os limites dos sonhos juvenis. Sua aposta fundamental evoca uma atitude adulta de equilíbrio e responsabilidade, imprescindível no que se refere a fazer do mundo social e da vida adulta modelos de organização, resistência, progresso. Diante dos modelos, a criança pode se apaixonar pelo mundo, se dispor a passar do universo de brincadeiras e sentimentos tranquilos para a esfera dos valores morais e dos desafios sociais e políticos que - muito embora desfaçam a ilusão de harmonia - revelam a instabilidade e, com ela, as brechas pelas quais se pode intervir no mundo.

Se, por um lado, cabe à escola introduzir a criança na esfera pública (Arendt, 2001), por outro, não há modo de fazê-lo sem tomar posição diante de temas dilacerantes como a guerra ou a exploração econômica. A escola precisa abordar os temas que provocam os homens e lhes fazem sofrer, registrar suas derrotas e conquistas, mas precisa também levar os alunos ao contato com obras cuja perfeição estética torna inaceitáveis o sofrimento e a exploração dos homens, atestando a verdade dos sonhos humanos e a legitimidade dos ideais de justiça, igualdade e democracia. O silêncio acerca de tais temas, longe de proteger das agressões do mundo, seria causa de descrença e dogmatismo. Quando a escola não se posiciona, deixa espaço para que a ideologia dominante se imponha com mais força.

$\mathrm{Na}$ escola progressista, pouco a pouco o contato com a cultura 
elaborada se apresenta como um movimento em que o aluno contrapõe suas primeiras apreensões sobre a realidade, suas experiências quotidianas e fragmentárias à unidade e à coerência da cultura universal, até o ponto em que poderá compreender que cada momento da luta quotidiana tem sua relação com a totalidade do processo histórico.

O que parece evidente à primeira vista, à cultura primeira, por exemplo, a população e sua divisão entre cidade e campo ou a "lei" da oferta e da procura, são percepções apenas parciais; elas só adquirem significado pleno em relação a categorias como o valor, a divisão do trabalho. Estas categorias não são dadas na experiência imediata [...] são o resultado de um trabalho cultural difícil. (Snyders, 1988, p. 52).

Ao instituir a escola como espaço no qual a alegria é fruto do afastamento intelectual, do contato com a cultura elaborada e da apreensão de verdades que explicam a realidade, o autor nos mostra que as possibilidades de unidade entre jovens e adultos não estão postas no âmbito das relações pessoais. Ao contrário, essa unidade supõe a inserção do jovem na cultura adulta e uma tomada de posição dos mais velhos em favor de seu mundo, de sua época, das construções que testemunham o valor da humanidade.

É importante notar que a autoridade docente se liga diretamente à ideia de que existe uma assimetria inegável entre crianças e adultos no que diz respeito à posse da cultura historicamente valorizada. Assimetria que, de um lado, justifica o direito de o adulto planejar o acesso da criança à cultura e, de outro, confere à autoridade docente uma natureza social. Em outras palavras, a autoridade do professor assume um caráter impessoal, não podendo ser atribuída ao indivíduo como ser isolado, mas apenas ao adulto considerado como participante da comunidade cultural.

Os alunos não devem ser submetidos aos humores, às decisões sempre mais ou menos arbitrárias de um homem, nem ao regulamento 
impessoal da escola; os alunos não têm de aprender a subordinação a um homem. Têm obrigação, em todos os sentidos do termo, com relação à cultura; pela autoridade do professor, eles vão se formar na hierarquia libertadora da cultura. (Snyders, 1988, p. 224).

O conceito de autoridade elaborado por Snyders está, portanto, ligado diretamente ao modo como o professor se coloca diante da cultura socialmente produzida e dos princípios éticos e políticos que ela representa. Desse modo, o autor inscreve sua pedagogia numa tradição alinhada não apenas com os desdobramentos educacionais do marxismo, mas também e, especialmente, com uma tradição especificamente pedagógica, bumanista, na qual reconhecemos, por exemplo, a obra de Georges Gusdorf.

Em continuidade com essa tradição pedagógica humanista, Snyders debate e afirma o caráter revolucionário das obras-primas universais. Por seus aspectos estéticos e culturais, as maiores obras da cultura elaborada, sustenta ele, se mantêm para além dos limites sociais, econômicos e políticos impostos pelo contexto em que foram criadas. A apropriação dessas obras por cada classe social é limitada não pelas características da obra em si, mas pela desigualdade de classes. Cada classe social luta para definir padrões e direitos de acesso à cultura elaborada, da mesma forma como luta por definir padrões e privilégios econômicos, e isso faz com que nem todos tenham acesso às grandes obras. A luta de classes é, desse modo, dialeticamente, arena de enfrentamento para garantir o acesso universal às obras-primas que mantêm identidade com o conjunto dos homens.

Não levar, não atrair os alunos para as grandes obras é de fato reserválas, continuar a reservá-las aos favorecidos socialmente, que terão sido cuidadosamente preparados fora da escola por suas famílias. [...] É consentir com os obstáculos materiais e ideológicos que a sociedade e seu modo de vida acumulam entre as obras-primas e eles, em vez de ajudá-los a tomar consciência desses obstáculos. (Snyders, 1994, p.161). 
Nesse ponto é que a intervenção da escola alcança seu sentido maior. Seu papel é realizar a reavaliação crítica da cultura elaborada e proceder a uma seleção de conteúdos pautada pelos princípios da dialética, de modo que permita ao aluno apreender a história como uma síntese das contradições. Nesse contexto, a natureza histórica das relações sociais e a unidade existente entre os progressos econômicos, as descobertas científicas e as criações artísticas aparecem como objeto de estudo, mas devem ser consideradas também como instrumentos revolucionários.

A certeza de que o mundo pode progredir, de que os avanços se sobrepõem às dificuldades e têm ajudado o homem a tomar posse de si e de seu mundo é, pois, o axioma sobre o qual Snyders elabora sua proposta para uma pedagogia progressista. Por isso o autor contesta, ao longo de sua obra, o valor progressista de teorias sociológicas e pedagógicas que insistem em negar a validade das conquistas democráticas.

as transformações são a regra da história [...] cabe-nos pois aproveitar, prolongar os ensaios, os esboços de progresso que já se anunciam. Não estamos reduzidos a imaginar utopias de felicidade. Em suma, a atualidade, enquanto saída da história, é para nós uma garantia contra o abandono. (Snyders, 1995, p. 96).

A desvalorização do mundo atual e a negação dos avanços sociais e políticos concorrem para a desvalorização do adulto, mas, longe de indicar uma valorização da criança, implicam a miséria da infância. Quando adere ao fatalismo das constatações sociológicas e nega as possibilidades de avanço social, é como se o adulto negasse também as mínimas porções de autonomia e transformação que cabem à juventude. Ao contrário, quando proclama a beleza e os problemas de sua época como verdadeiros, o adulto assume sua porção de autoria e responsabilidade em relação à construção da história e coloca-se como interlocutor para uma juventude que precisa de ajuda para decifrar os códigos adultos. 
Ao declarar que o mundo contém progressos potenciais, é como se o adulto proclamasse também o valor da juventude, seu espaço e papel na edificação de projetos que, enfim, as gerações partilham. $\mathrm{E}$ isso faz com que o jovem aprenda a confiar em si mesmo. A escola progressista é, nesse sentido, síntese de proteção e encorajamento.

\section{A escola como espaço de unidade entre pensamento e ação}

Snyders afirma, de modo veemente, a possibilidade e a urgência de que as crianças da classe operária encontrem, na escola, a mesma satisfação cultural proposta para os filhos das classes dominantes; uma alegria fundada sob o signo da compreensão e do autodomínio e que por ser assim não ocorre de imedito, logo de entrada na escola.

Mais envoltas pela cultura dominante, menos convencidas quanto às compensações profissionais para esforços culturais e mais profundamente ligadas às limitações impostas pelas emergências da vida quotidiana, as crianças do proletariado são, para Snyders, as que mais necessitam se inserir no universo escolar e encontrar nele ambiente atrativo, capaz de reiterar esforços de atenção e disciplina intelectual e o interesse pela cultura elaborada. Por isso, a transmissão, na escola, de uma cultura fragmentária (que não está ligada aos verdadeiros anseios populares nem consegue traduzir a cultura elaborada) é considerada, por ele, um absurdo. Manter o aluno no nível das primeiras hipóteses explicativas, julgá-lo incapaz de compreender as produções de excelência indica uma atitude que não apenas nega o papel para o qual a instituição escolar foi criada, como também provoca a resignação dos mais explorados:

A maior parte das crianças em situação de fracasso são as de classe popular e elas precisam ter prazer em estudar; do contrário, desistirão, abandonarão a escola, se puderem. Se não puderem, continuarão, mas não aprenderão muito. Quanto mais os alunos enfrentam dificuldades - de ordem física e econômica - mais a escola deve ser 
um local que lhes traga outras coisas e um tipo de satisfação que não encontrariam em outro lugar... A alegria deve ser prioridade para aqueles que sofrem mais fora da escola. Sei que é um pouco utópico, mas de vez em quando é necessário sonhar. (Snyders, 1990 apud De Camillis, 1990, p. 164).

Os jovens das classes exploradas devem poder contar com a escola para ultrapassar os limites impostos pela desigualdade de classes, tanto no que se refere às práticas de vida e trabalho quanto no que diz respeito aos objetivos que desejam alcançar. A cultura escolar pode e precisa funcionar como contraponto da sociedade, ou melhor, como contraponto das teorias que pensam a sociedade e o capitalismo como realidades absolutas e estáticas. E isso não porque a educação deva incitar a revolta indiscriminada contra os valores estabelecidos, mas por ser capaz de afirmar a legitimidade de projetos democráticos, a possibilidade de compreender e de transformar a realidade histórica.

O que Snyders admira e quer preservar na juventude é sua capacidade plena de encantar-se com o mundo para não se manter indiferente às suas misérias; é a força de sua indeterminação; seus múltiplos potenciais - características que representam o avesso dos determinismos impostos pelo mundo do trabalho. Por isso, o autor rejeita a especialização precoce dos estudantes, o que não apenas limita o universo de inserção cultural da criança, mas também arrisca a dar continuidade ao ciclo de exclusões sociais.

Os modelos de escolarização profissionalizante - afirma o autor - não guardam espaço para tentativas, para o aperfeiçoamento paulatino ou para a artificialidade de exercícios cujo objetivo único é permitir a aprendizagem. Desse modo, negam a especificidade escolar em função de uma realidade restrita, limitada pelo futuro profissional. De uma só vez, renunciam a acolher as preocupações juvenis em sua integridade e a estendê-las à compreensão transformadora. 
O momento no qual será necessário que o aluno se especialize certamente chegará; mas é preciso que a escola transmita aos jovens, durante todo o tempo que lhe for possível, o sentido da cultura no seu conjunto, o sentido da unidade da cultura. (Snyders, 1994, p. 18).

A cultura escolar deve, portanto, estender as revoltas pressentidas e o descontentamento que emerge em virtude das vivências reais à coerência da cultura elaborada. O conceito de continuidade-ruptura significa, de um lado, que o jovem precisa se sentir acolhido pela escola e por sua cultura; e, de outro, que o conjunto dos conhecimentos mais complexos, a amplitude estética das grandes obras e o teor progressista de textos e autores escolhidos exigem rigor no processo pelo qual o aluno se apropria do conhecimento. Acolher o aluno e a urgência de seu mundo é, nesse sentido, dialeticamente afastá-lo das urgências quotidianas para preparar uma inserção cultural permeada por explicações, sínteses e beleza.

é essencialmente na medida em que a escola tem vontade de impor aos alunos uma cultura que não mantém relação profunda com o que os atrai, o que eles já experimentaram, adquiriram eles mesmos que a incompreensão torna-se vazia e aumenta o risco de autoritarismo. (Snyders, 1988, p. 216).

\section{A escola como espaço de confronto entre a cultura elaborada e a cultura de massas}

Muito embora Snyders fundamente toda a sua obra na proposição de uma escola capaz de restaurar a síntese entre cultura primeira e cultura elaborada, não há, em seus livros, uma discussão sistemática sobre o senso estético ou sobre o caráter animista (Bosi, 1994) da cultura popular. O autor não faz menção específica aos elementos criativos dessa cultura - a não ser àqueles tomados na análise da cultura operária -, fator que, ao mesmo tempo, marca a posição de 
silêncio de Snyders diante das polêmicas e nos impede de discutir com clareza o lugar de atuação da cultura escolar em uma sociedade na qual são crescentes o relativismo cultural e os processos de aculturação.

Embora enuncie a indivisibilidade (Bosi, 1994) da cultura popular, ou seja, o fato de que ela é feita de saberes práticos, resistência política e elementos impostos pela cultura dominante, seus textos não nos permitem contemplar a força da cultura popular como modo de vida em que se produzem elementos de beleza e identidade. Talvez por isso, em sua obra, a cultura popular apareça tão diluída na cultura de massas.

A cultura do povo é, sempre, em Snyders, cultura primeira, na qual pesam, sobretudo, os preconceitos de classe, o determinismo histórico e social, o conservadorismo político, as vivências quotidianas e as alegrias imediatas. Todavia, desde a publicação de Alegria na escola (1988), essa cultura é apresentada pelo autor quase como uma função da cultura de massas: tende para a simplificação da realidade, supervaloriza o contemporâneo, espelha, mas não se identifica com o homem comum, e encanta, sobretudo, pela força de suas imagens, caricaturas, temas emotivos:

Vejo que a escola é fundamentalmente o lugar onde as obras primas da cultura possam ser apresentadas aos alunos e seja o único lugar onde haja oportunidade de encontrar os grandes poetas, os grandes pensadores, os grandes sociólogos, porque no resto do tempo há a TV, onde se distrai com os amigos, e aí as obras primas são raras. A escola é o lugar onde se apresentam as obras primas e onde se preparam as condições para que os alunos as compreendam. (Snyders, 1995 apud Klein, 1995, p. 144).

Se a cultura popular supõe, na obra de Snyders, uma certa sabedoria empírica (Bosi, 1994), por outro lado, não guarda a capacidade de registrar seus saberes sob a forma de produções artísticas organizadas. E é sempre com essa cultura primeira - 
marcada pela fragmentação da cultura de massas e pela incoerência da cultura operária - que a cultura escolar deve manter continuidades e rupturas.

Snyders aponta como o grande limite da cultura primeira a tendência a construir estereótipos e simplificações que tornam imediatamente seguras as apreensões sobre o mundo e não indicam qualquer movimento em direção à contestação das estruturas sociais. Nesse sentido, o que de fato importa é que a inserção no universo cultural escolar resulte em formas mais coerentes de agir para a transformação da sociedade, em modos de agir coletivos, organizados em favor dos interesses de classe: "não está em jogo um progresso apenas intelectual, na compreensão; é preciso simultaneamente ação, até que se atinja uma existência modelada pela cultura elaborada..." (Snyders, 1988, p. 93). O autor afirma que uma ação pedagógica voltada para a inserção dos alunos no universo cultural escolar deveria, a princípio, centrar-se na certeza de que a cultura do trabalho - na qual estão imersos pais e filhos da classe operária - contém uma série de aspectos positivos capazes de provocar satisfação cultural: o domínio de técnicas de produção que dá início às primeiras apreensões científicas; o contato direto com as máquinas mais avançadas, capaz de provocar certo grau de admiração e confiança no que se refere ao progresso social; uma solidariedade espontânea que aponta para a unidade possível entre as massas trabalhadoras... Mas, se os operários percebem a exploração, é preciso aprender a pensar sobre ela; se reivindicam mudanças, é preciso reconhecer a distância entre elas e as lutas revolucionárias; tecem uma solidariedade espontânea fundamentada exclusivamente na força de necessidades materiais; é preciso confrontá-la com as possibilidades de uma luta contínua, organizada e orientada politicamente. A inserção no universo da cultura elaborada deve significar a extensão da unidade entre ação e pensamento. Isto, longe de declarar a morte da cultura popular, confere às preocupações quotidianas o estatuto de objeto de estudo.

a renovação da escola é de início uma renovação dos conteúdos 
ensinados tal como conduzem à satisfação [...] Estes deverão ser portanto conteúdos culturais ligados à vida das massas, ao que melhor sustentou as massas, nas suas lutas e aspirações. (Snyders, 1988, p. 108).

\section{A escola como espaço de continuidade-ruptura com a cultura popular}

A escola deve realizar, então, uma seleção cultural pautada por dois pontos centrais: primeiramente, reconhecer as obras-primas universais e, depois, abordar tais obras de modo sistemático e progressista, de uma maneira que se mantenha a continuidade-ruptura entre a cultura escolar e a cultura popular. Sua tarefa é preparar, ou melhor, assegurar o contato dos alunos com a cultura erudita, o que, na esfera institucional, significa não apenas a seleção de conteúdos específicos e a reavaliação crítica dos conteúdos, mas também a imposição de obrigações e regras impessoais capazes de instituir um universo cultural escolar em que o peso das desigualdades de classe e a fragmentação da cultura popular têm como contraponto a sistematicidade das práticas escolares e a universalidade das obras-primas.

Nesse sentido, os rituais escolares (Boto, 2002) marcam não apenas o desnível fundamental entre as tarefas escolares e a vida habitual, mas também certificam que o conhecimento dosado, adquirido às custas de esforço e atenção, pode levar à alegria de conhecer os segredos adultos e de compreender seu mundo, em uma esfera para a qual a criança não se voltaria espontaneamente.

Organização sistemática das situações de aprendizagem; adaptação do conteúdo ao público esperado; gradação coerente dos saberes; continuidade que permite regressos, retomadas, aperfeiçoamento e construção de hábitos: em conjunto, essas práticas estruturam o mundo escolar, marcando os limites e a legitimidade da autoridade docente, fundamentando uma nova relação entre a criança e o conhecimento. 
Alegria de evoluir na coerência, de descobrir e de instituir a coerência [...] Progressão sistemática: vai-se por etapas, sem queimar etapas, sem saltar de uma questão a outra antes de ter terminado a primeira: não se fala de uma coisa e logo em seguida de uma outra. As dificuldades contêm-se, encadeiam-se: elas constituem um programa que não dá a impressão de ter sido escolhido arbitrariamente pela instituição... (Snyders, 1988, p. 100).

As regras instituídas para organizar esse universo escolar desempenham papel explicitamente moral: de valor universal, favorecem uma importante condição de igualdade para todos os alunos; igualdade que permite à criança e ao jovem não apenas se sentirem à altura dos demais alunos para ousarem descobrir o que desconhecem, mas também - e especialmente - igualdade que faz sentir a força de medidas justas limitando suas próprias ações sobre os outros e o poder dos outros sobre si.

Georges Snyders traz-nos, assim, os imperativos de sua pedagogia progressista: manter a especificidade do universo escolar, mas renovar os conteúdos de modo a que se possa caminhar em direção à alegria cultural.

\section{Conclusão}

Ao percorrer a obra de Georges Snyders deparamo-nos com um modo próprio de pensar a educação, no qual importa, sobretudo, declarar explicitamente as apostas que se faz, os perigos que se pretende transpor, as convicções com as quais assumimos a autoridade e a responsabilidade de educar a juventude.

O que importa guardar como centro de sua pedagogia é a necessidade de renovar os conteúdos escolares em um movimento que implica síntese entre tradição e mudança. A tradição é aquela instaurada no campo da cultura produzida pela escola, aquilo a que Boto (2003) chama de "liturgia escolar", centrada sobre a transmissão da cultura 
letrada e de códigos de civilidade. A mudança na escolarização é, por sua vez, instada pela abertura de um campo que debate temas polêmicos universais ou quotidianos, que afirma e esclarece as chances de transformação da sociedade, a despeito de reconhecer, contraditoriamente, riscos de inculcamento, opressão, controle.

A primazia da escola na construção de relações entre a criança e o conhecimento acontece pela proposição de uma outra cultura, diferente do senso comum: cultura que coloca a criança em face dos grandes temas que instigam e ameaçam a sobrevivência; cultura que abraça e estende as preocupações quotidianas levando-as ao ponto máximo de emoção e complexidade; cultura que abarca, fundamentalmente, o pensar sobre a realidade e, por isso, patamar em que a criança ousa experimentar, questionar o óbvio, transpor os limites da coerência instaurada, pensar a utopia de um mundo melhor.

A superação de preconceitos culturais exige questionamento, aquisição de saberes explicativos e compreensão racional das distâncias que marcam a relação entre povos, classes sociais e grupos étnicos diferentes pela superação de uma suposta contradição entre o particular e o universal. De alguma maneira, essa é a função da escola. Em suma, é fundamental que se faça da experiência vivida um objeto de crítica e explicação consciente, de forma que o aluno se aproprie das possibilidades históricas de construir uma convivência mais justa e igualitária.

Snyders apresenta-nos a criança como portadora de uma moral contraditória: ao mesmo tempo em que deseja partilhar sentimentos, integrar-se ao mundo, conhecer e se perder num universo desconhecido, a criança teme a diferença, deixando-se conduzir pelo universo de expressões e percepçõesdo senso comun. Por isso, para o autor, é indispensável a intervenção da escola no sentido de - a um só tempo - atender aos impulsos infantis e juvenis de integração (garantindo a convivência entre crianças diferentes) e pôr em debate atitudes de exclusão anteriormente tidas como naturais. 
Para sustentar ideais de igualdade e justiça, é necessário que as pessoas aprendam a viver juntas, saibam respeitar a si e aos outros, a sua própria identidade e a identidade do outro que é, por definição, o diferente. Todavia nenhuma habilidade técnica ou cognitiva, nenhuma maneira de organizar os espaços e atividades, nenhum método de ensino e aprendizagem carrega em si mesmo a capacidade de fazer com que seu adepto respeite o outro, abra-se ao contato e diálogo com ele; e isso porque respeitar outros homens - sejam eles quais forem, independentemente de sua raça, etnia, religião, sexo ou idade - é uma atitude, uma escolha moral; mais que moral, ética. Passa, portanto, pela apreensão e compreensão de um conceito universal de homem.

O debate pedagógico precisa - afirma Snyders - superar a dúvida a respeito de se devemos ensinar conteúdos clássicos ou populares, universais ou identitários, porque a edificação de sociedades mais justas supõe a integração de ambas as dimensões da cultura e não a superposição de uma sobre a outra.

A arquitetura escolar e seus usos instituídos asseguram a convivência de múltiplos e contrários em um espaço que marca, seleciona e classifica. A regularidade das atividades prescritas possibilita, por sua vez, abordar e retomar conteúdos definidos; proceder aos exercícios, repetições, explicações; cuidar para um contato gradual com obras difíceis. É numa tal condição de constância que a intervenção docente pode mostrar toda a sua abrangência: ao professor cabe a responsabilidade de definir temas e debates, problematizar os conflitos que emergem da convivência, tornando explícitos os fundamentos sociais de atitudes preconceituosas, o alcance superficial de afirmações e escolhas marcadas pelo ceticismo, a fragmentação das informações, a incoerência dos pressupostos.

Os rituais escolares enunciam, sim, um tipo específico de autoridade: autoridade contida no domínio de um mundo em que o aluno é sempre novo, inexperiente; autoridade impingida pela métrica temporal e espacial; autoridade legítima porque contraponto da responsabilidade por assegurar a tranquilidade dos estudos, a 
regularidade dos encontros, a universalidade das regras. Mas não só de rituais se faz a autoridade docente.

Se o respeito dos alunos legitima a autoridade do professor e faz dele um mestre (Araújo, 1999), é porque, para além das regras que cumpre e faz cumprir, o professor conseguiu - no confronto com os alunos - transmitir-lhes o valor de suas apostas em favor do mundo e dos homens, a verdade de suas convicções. Isto porque há tempos que não se regulam os tempos da partilha, os tempos da identidade, o tempo existente entre o conhecer e o querer ensinar.

Para romper com preconceitos arraigados, para superar as dicotomias de um pensamento que exclui e também sujeita, a criança precisa confrontar-se com autores e obras que funcionem como parâmetros de perfeição e veracidade, que atestem a beleza da humanidade e a unidade dialética da história, modelos que não apenas afirmem a verdade, mas que provoquem a discussão e a reconstrução mais complexa daquilo que, a princípio, o estudante compreende ser verdadeiro, correto ou natural.

Se as atividades escolares propõem um misto de imitação dos modelos e originalidade, a cultura escolar não é cultura de negação. Diante dela, o aluno não tem de abandonar sua cultura de origem, negar a cultura popular, abraçar outras lutas que não a sua. $\mathrm{O}$ direito da escola sobre a vida de seus estudantes, o direito de afastar crianças, adolescentes e jovens de sua casa e de sua família, o direito de substituir alegrias imediatamente comunitárias pela alegria produzida na própria dificuldade do trabalho intelectual se confundem - em Snyders - com a capacidade de instituir, entre o senso comum e a cultura elaborada, sínteses de continuidade e ruptura.

Sobre a vida de um menino, seus sonhos, fantasias, suas esperanças e mágoas, seus jeitos de interpretar o mundo, de sentir felicidade, a escola intervém, geralmente, pela exposição de um repertório cultural que lhe ajude a aprimorar sua concepção de mundo, que funcione como instrumento com o qual a criança reconhece os interesses de sua classe social, as dificuldades de sua família e de seus 
companheiros como parte de lutas maiores, universais. $\mathrm{Na}$ esteira de tais convicções, o testemunho de Canetti (1987) evoca - de modo surpreendente e acolhedor - as alegrias enunciadas por Snyders:

Porque o que havia de verdadeiramente novo, o que em realidade me arrebatou naquela escola, foi a história da Grécia. Estudávamos os livros de Ochsli, um de história geral e o outro de história da Suíça. Me lancei sobre ambos e os li até o fim, passando de um para o outro com tanta rapidez, que se converteram num só livro, para mim. A liberdade dos suíços coincidiu com a dos gregos. [...] Percebi a libertação dos suíços como um fato atual e a senti em mim mesmo [...] Os imperadores, como senhores supremos da guerra, eram-me suspeitos [...] Não era menor minha prevenção contra os czares da Rússia. Aos dez anos, durante uma visita à Bulgária, eu ouvira o nome de Tolstói e explicaram-me que era um homem maravilhoso que considerava as guerras como assassinatos e que não tivera medo de dizê-lo aos seus imperadores. Falavam dele que já estava morto como se não tivesse morrido realmente. Agora, pela primeira vez, eu me encontrava numa república, longe de todas as mazelas imperiais; lancei-me com avidez sobre a história. Era possível libertar-se de um imperador; era necessário lutar pela liberdade. (Canetti, 1987, p. 170-171).

\section{Fontes}

DE CAMILLIS, L. S. Entrevista com Georges Snyders. 1990. Disponível em: <http://www. https://periodicos.ufsc.br/index.php/zeroseis/article/ view/2069>. Acesso em: 15 maio 2003.

KLEIN, L. F. Entrevista com o professor Georges Snyders. Revista da Faculdade de Educaşão, São Paulo, v. 21, n. 2, p. 139-147, jul./dez. 1995.

SNYDERS, G. Pédagogie en France aux XVII et XVIII siècles. Paris: Presses Universitaire de France, 1965.

SNYDERS, G. Pedagogia progressista. Coimbra: Almedina, 1974. 
SNYDERS, G. A Pedagogia em França nos séculos XVII e XVIII. In: DEBESSE, M.; MIALARET, G. Tratado das Ciências pedagógicas: história da pedagogia. São Paulo: Companhia Editora Nacional; Editora da Universidade de São Paulo, 1977, p. 269-334.

SNYDERS, G. Escola, classe e luta de classes. 2. ed. Lisboa: Moraes, 1981.

SNYDERS, G. Não é fácil amar nossos filhos. Lisboa: Dom Quixote, 1984.

SNYDERS, G. A alegria na escola. São Paulo: Manole, 1988.

SNYDERS, G. Escola e democratização do ensino. Educação em questão, Natal, v. 3, n. 2, jul./dez. 1989, p. 86-103.

SNYDERS, G. Alunos felizes. São Paulo: Paz e Terra, 1993.

SNYDERS, G. A escola pode ensinar as alegrias da música? São Paulo: Cortez, 1994.

SNYDERS, G. Feliz na universidade. São Paulo: Paz e Terra, 1995.

SNYDERS, J. C. Drames enfouis. Paris: Buchet/Chastel, 1996.

SNYDERS, G.; LÉON, A.; GRACIO, R. Correntes atuais da pedagogia. Lisboa: Livros Horizonte, 1984.

\section{Referências}

AGGIO, A. O que morre com o comunismo. Presença-Revista de Politica e Cultura, nov. 1991/mar. 1992, p. 17-21.

AGGIO, A. (Org.). A vitalidade de um pensamento. São Paulo: Editora da Unesp, 2002.

ALAIN, E. C. Reflexões sobre a educação. São Paulo: Saraiva, 1991.

ALTHUSSER, L. Aparelhos ideológicos do Estado. 8. ed. Rio de Janeiro: Graal, 2001.

AQUINO, J. G. Autoridade docente, autonomia discente: uma equação possível e necessária. In: AQUINO, J. G. (Org.). Autoridade e autonomia: Alternativas teóricas e práticas. 2. ed. São Paulo: Sumus, 1999, p. 131-153.

ARAÚJO, U. F. de. Respeito e autoridade na escola. In: AQUINO, J. G. (Org.). Autoridade e autonomia: Alternativas teóricas e práticas. 2. ed. São Paulo: Sumus, 1999.p. 101-114.

ARENDT, H. Entre o passado e o futuro. 5. ed. São Paulo: Perspectiva, 2001. 
ARIÈS, P. História social da família e da criança. 2. ed. Rio de Janeiro: Zahar, 1981.

BAUDELOT, C.; ESTABLET, R. La escuela capitalista. 8. ed. Madrid: Siglo veintiuno de España editores, 1986.

BOSI, A. Cultura brasileira. In: MENDES, D. T. (Coord.). Filosofia da educação brasileira. 5. ed. Rio de Janeiro: Civilização Brasileira, 1994, p. 135-176.

BOTO, C. Teóricos militantes: entre debates e dilemas, as interfaces da esquerda. Araraquara, 1991. Mimeografado.

BOTO, C. A pedagogia sob o signo da política: Gramsci educador. Didática (Unesp, Marília), São Paulo, v.31, 1996, p.21-27.

BOTO, C. O desencantamento da criança: entre a Renascença e o Século das Luzes. In: FREITAS, M. C; KUHLMANN Jr., M. Os intelectuais na história da infância. São Paulo: Cortez, 2002.

BOTO, C. A civilização escolar como projeto político e pedagógico da modernidade. Caderno Cedes, v.23, n.61, dez. 2003, p. 378-397.

BOURDIEU, P.; PASSERON, J. C. Reprodução cultural e reprodução social. In: BOURDIEU, P. Economia das trocas simbólicas. São Paulo: Perpectiva, 1974, p. 294-335.

BOURDIEU, P.; PASSERON, J. C. A reprodução. 3. ed. Rio de Janeiro: Livraria Francisco Alves, 1975.

CANETTI, E. A lingua absolvida: história de uma juventude. São Paulo: Companhia das Letras, 1987.

CARVALHO, J. S. F. Construtivismo: uma pedagogia esquecida da escola. Porto Alegre: Artmed, 2001.

CORDEIRO, J. F. P. Falas so novo, figuras da tradição: O novo e o tradicional na educação brasileira (anos 70 e 80). São Paulo: Editora Unesp, 2002.

DURKHEIM, E. Educação e sociologia. São Paulo: Melhoramentos, 1978.

DURKHEIM, E. A evolução pedagógica. Porto Alegre: Artes Médicas, 1995.

FOUCAULT, M. Vigiar e punir: história da violência nas prisões. 9. ed. Petrópolis: Vozes, 1991.

GRAMSCI, A. Os intelectuais e a organização da cultura. 2. ed. Rio de Janeiro: Civilização Brasileira, 1978.

GRAMSCI, A. Cadernos do cárcere. 2. ed. Rio de Janeiro: Civilização Brasileira, 2001.v. 3. 
GRIGNON, C. Cultura dominante, cultura escolar e multiculturalismo popular. In: SILVA, T. T. (Org.) Alienígenas na sala de aula. Petrópolis: Vozes, 1998. p.178-189.

GUSDORF, G. Professores para quê? Para uma pedagogia da pedagogia. 3. ed. São Paulo: Martins Fontes, 2003.

ILLICH, I. Sociedade sem escolas. 2. ed. Petrópolis: Vozes, 1973.

LUKÁCS, G. História e consciência de classes. Porto: Publicações Escorpião, 1974.

MANACORDA, M. A. O princípio educativo em Gramsci. Porto Alegre: Artes Médicas, 1990.

MÉTODO pedagógico dos jesuítas. In: FRANCA, Pe. Leonel. Obras completas -X. Rio de Janeiro: Agir, 1952.

NOGUEIRA, M. A. Em defesa da politica. São Paulo: Senac, 2001.

NOSELLA, P. A escola de Gramsci. Porto Alegre: Artes Médicas, 1992.

PATTO, M. H. S. A produção do fracasso escolar: histórias de submissão e rebeldia. 2. ed. São Paulo: Casa do Psicólogo, 1999.

PERRENOUD, P. Ofício de aluno e trabalho escolar. Porto: Porto Editora, 1995.

PETITAT, A. Produção da escola/produção da sociedade: análise sócio-histórica de alguns momentos decisivos da evolução escolar no Ocidente. Porto Alegre: Artes Médicas, 1994.

POSTMAN, N. O desaparecimento da infância. Rio de Janeiro: Graphia, 1999.

ROUSSEAU, J.-J. Emílio ou Da Educação. São Paulo: Martins Fontes, 1995. 